\title{
UN NUEVO OPERADOR DEL DESACUERDO: ¿HOLA?
}

\section{A NEW DISCOURSE MARKER OF DISAGREEMENT IN SPANISH: ¿HOLA?}

\author{
DAmiÁn Moreno Benítez \\ Universidad de Sevilla. \\ Grupo Argumentación y Persuasión en Lingüística \\ damian.moreno.benitez@gmail.com
}

Recibido: $17 / 06 / 2019$

Aceptado: 20/10/2019

\begin{abstract}
Resumen
Se analiza la evolución de un marcador fático, la interjección hola, hacia un operador argumentativo del desacuerdo en el registro coloquial. A partir de la Lingüística Pragmática y la teoría de la argumentación se analizan ejemplos reales tomados del corpus oral y digital del grupo Argumentación y Persuasión en Lingüística. La novedad es que un operador cohesivo e interactivo como hola, cuya función prototípica es la apertura del discurso, puede evolucionar a un operador modal y argumentativo. En el plano modal expresa sorpresa y en el argumentativo desacuerdo y posible descortesía.

PALABRAS CLAVE: marcadores discursivos; desacuerdo; modalidad; argumentación.
\end{abstract}

\begin{abstract}
We analyze the evolution of a phatic discourse marker, the Spanish interjection hola, towards a argumentative marker of disagreement in colloquial language. From the Pragmatic Linguistics and Argumentation Theory, we analyze real examples in oral and digital corpus of Argumentación y Persuasión en Lingüística group. The novelty is that the interactive and cohesive marker hola, that functions to open the speech, can become a marker of modality and argumentation. This new marker express surprise in the modal level and it says disagreement and impoliteness in the argumentative level.

KEY WORDS: discourse markers; disagreement; modality; argumentation.
\end{abstract}

\section{INTRODUCCIÓN}

En los ya numerosos estudios sobre los marcadores discursivos se suele comprobar cómo en la evolución que va desde una forma léxica plena, sea un adverbio, una conjunción o incluso un sustantivo, un verbo (Álvarez-Egzenberg 2015), un grupo de palabras, etc., has-

Para citar este artículo / To cite this article: Moreno Benítez, Damián (2019): "Un nuevo operador del desacuerdo: ¿hola?”. González Sanz, Marina y Pérez Béjar, Víctor (eds.): ELUA: Macrosintaxis en construcción, Anexo VI, págs. 157-172.

Enlace/Link: http://dx.doi.org/10.14198/ELUA2019.ANEXO6.09 
ta llegar a la configuración del propio marcador, se observa una desemantización progresiva del término que es característica del proceso de pragmaticalización, o gramaticalización sin más, si entendemos la gramática en sentido amplio o macrosintáctico (Fuentes, 2017). Es decir, el elemento en cuestión pasa de actuar en el plano oracional a funcionar en el plano discursivo y, en ese progresivo ascenso de la microestructura a la macroestrutura, puede ir adquiriendo determinadas funciones pragmáticas al tiempo que va perdiendo sus valores léxicos hasta adquirir un valor meramente instrumental. En marcadores como hombre, vamos, ¿sabes?, dale se ve una evolución en ese sentido que acaba en un uso meramente enfático o fático.

En cambio, en el caso de ¿hola? vemos una progresión inversa. Partimos de un marcador fático de inicio del intercambio comunicativo, con apenas contenido léxico, más que el instrumental de apelación al oyente, de saludo cortés y de inicio conversacional, que va a evolucionar a un operador modal y argumentativo de sorpresa y desacuerdo. Se trata de un nueva función pragmática que hemos observado en el lenguaje coloquial, concretamente en el lenguaje conversacional utilizado en las redes sociales, es decir, en el discurso mediado por dispositivo digital.

Nuestro objetivo ${ }^{2}$, por tanto, es explicar y analizar este nuevo operador del desacuerdo teniendo en cuenta los presupuestos de la Lingüística Pragmática (Fuentes 2001, 2013, 2014, 2017[2000]) y la teoría de la argumentación expuesta en Fuentes y Alcaide (2002), de manera que al constatar la multidimensionalidad y polifuncionalidad de los marcadores discursivos podamos arrojar luz sobre el proceso de creación y gramaticalización de dichos elementos.

Para ello, analizaremos supuestos reales tomados del material oral y digital del grupo APL (Argumentación y Persuasión en Lingüística, HUM659): corpus MEsA, donde se recogen conversaciones en diferentes redes sociales o aplicaciones de intercambio comunicativo: Twitter, Facebook, Instagram, Whatsapp, Youtube.

En primer lugar, expondremos brevemente los postulados teóricos de los que partimos y las características metodológicas de este tipo de material mediado por dispositivo digital. Luego, recogeremos la información que nos aportan los diccionarios, gramáticas y trabajos monográficos sobre "Hola". A continuación, analizaremos las características discursivas del nuevo operador, para, seguidamente, proponer una explicación del origen de dicha función $\mathrm{y}$, por último, llegar a unas conclusiones.

\section{OPERADORES MODALES Y ARGUMENTATIVOS}

Seguimos la propuesta modular y jerárquica de la Lingüística pragmática formulada por Fuentes (2013, 2015[2000], 2017), que distingue en el análisis del discurso distintos niveles y planos. La microestructura se refiere grosso modo a la codificación de la sintaxis oracional, a los fenómenos fonológicos, léxicos, semánticos y gramaticales de las unidades oracionales o inferiores a la oración. En la macroestructura nos situamos en la unidad mínima del enunciado y en la máxima del texto. Aquí hay un salto de nivel, pues a los factores gramaticales intrínsecos del código hay que sumar el contexto comunicativo en sentido amplio. Es decir,

2 Este trabajo se enmarca en el Proyecto de Excelencia I+D De Construcciones Periféricas a Operadores Discursivos: un Estudio Macrosintáctico del Español Actual (Referencia: FFI2017-82898-P) del Ministerio de Economía y Competitividad, Gobierno de España. 
en la macroestructura intervienen unos interlocutores (hablante y oyente) en una situación comunicativa dada. Por último, también es determinante en la configuración del discurso la superestructura (Van Dijk, 1983), es decir, la tipología textual en la que se inserta una determinada secuencia textual. Ello tiene que ver con la finalidad del texto, pero también con los géneros textuales que nos proporciona la tradición idiomática. Es un camino de ida y vuelta, puesto que la asunción de un determinado género textual implica una determinada configuración de la micro y macroestructura textual y, a su vez, determinados fenómenos micro o macroestructurales hacen conformar la especificidad de un determinado discurso. En estos niveles de análisis interactúan los distintos planos pragmáticos. Los planos informativo y argumentativo surgen de la adecuación del texto al oyente o receptor (Fuentes, 2015[2000]: 52): qué sabe y qué desconoce (plano informativo) y cómo argumenta el hablante para convencerlo (plano argumentativo). Los planos enunciativo y modal, por su parte, muestran la intervención del hablante en su discurso y afectan tanto a la macro como a la microestructura. Pero, mientras que la enunciación se refiere al hecho metalingüístico del decir y de asumir la responsabilidad de lo dicho, la modalidad apunta a la actitud subjetiva del hablante con respecto a lo que emite: Yo digo una información X con una actitud subjetiva que manifiesto (Fuentes, 2005a: 122).

Los marcadores discursivos funcionan en la macroestructura textual, son tipos de palabras específicos del funcionamiento macrosintáctico (Fuentes, 2017: 11) e intervienen en cada uno de esos planos. Dentro de ellos podemos distinguir dos grandes grupos (Fuentes, 2017: 13): conectores y operadores. Los primeros tiene una función relacional, ya que unen enunciados y párrafos, y los segundos operan dentro del enunciado, sea sobre todo el enunciado, apareciendo entonces en la periferia, sea sobre un segmento del propio enunciado, hallándose en el interior del enunciado, y tienen una función en algunos de los planos pragmáticos: informativo, enunciativo, modal o argumentativo. Es habitual que cada operador se especialice en una determinada función pragmática, pero no siempre es así, ya que, por una parte, hay que observar el grado de gramaticalización (Traugott y Trousdale, 2010) o pragmaticalización del operador, en el caso de que esté en vías de fijación, y, por otro lado, también hay que tener en cuenta el frecuente valor multimodal de estos elementos, que según los contextos pueden adquirir valores modales o argumentativos o ambos simultáneamente, como hemos observado, por ejemplo, al estudiar el funcionamiento de los vocativos (Moreno Benítez, 2019).

\section{CARACTERÍSTICAS ESPECÍFICAS DEL DISCURSO MEDIADO POR DISPO- SITIVO DIGITAL (MÓVIL, ORDENADOR, TABLETA...)}

Los textos recogidos en dispositivos digitales conforman un discurso escrito con características orales o conversacionales (Briz 1998, Crystal 2001, Fuentes 2017[2000]): relación de proximidad entre los interlocutores, escasa planificación, toma de turno no predeterminada y predominio del registro coloquial, aunque en algunos casos hay una aproximación a registros formales y escritos. Se puede decir que nos situamos en un discurso híbrido en el continuum oral-escrito y coloquial-formal como sostienen Koch y Oesterreicher (1990 [2007]) y Narbona (2000).

De hecho, las redes sociales son un nuevo canal comunicativo (Pano y Mancera 2014; Padilla 2016) donde los intercambios se suceden linealmente de forma asincrónica, a dife- 
rencia de lo que ocurre en la conversación cara a cara. Se emplean herramientas multimodales características de cada red social o aplicación: Twitter (TW), Facebook (FB), Instagram (IG), Whatsapp (WA), Youtube (YT) ${ }^{3}$. Cada una tiene sus propias peculiaridades, desde la limitación espacial de Twitter hasta los característicos grupos de Whatsapp, pasando por el predominio de imágenes en Instagram y Youtube o los "me gusta" de Facebook. En la mayoría se pueden intercambiar comentarios, entrecruzar conversaciones, reproducir intervenciones que se comentan o contestan, seguir hilos temáticos, añadir enlaces, etc. Se utilizan determinados sistemas de mención del usuario, como “@usuario” en Twitter e Instagram o el hashtag \# para etiquetar el hilo de conversación. Además, es habitual el uso de instrumentos propios del medio digital que sustituyen a los elementos suprasegmentales (emoticonos, signos de puntuación, onomatopeyas, imágenes, gifs, memes...) debido a que se trata de una comunicación mediada por dispositivo digital y no existe necesariamente copresencia de los interlocutores.

Por otro lado y teniendo en cuenta estas especificidades del medio, el hecho de que se trate de un discurso poco planificado, con características fundamentalmente orales y coloquiales, transcrito por los propios usuarios, al mismo tiempo que muestra numerosas imperfecciones de carácter tanto técnico (la rapidez en teclear o en pulsar los caracteres en el móvil, donde es fácil el baile de letras, por ejemplo) como individual o personal, ofrece, por esto mismo, un material de un valor inestimable para el lingüista, pues refleja fielmente la lengua en uso (Yus, 2010).

\section{HOLA, EL MARCADOR FÁTICO DE SALUDO E INICIO CONVERSACIONAL}

Se trata de la forma de saludo más generalizada en el español actual. Se puede utilizar como saludo exclusivamente $\mathrm{y}$, como tal, puede constituir un enunciado autónomo, pero lo más habitual es que funcione como el inicio del intercambio comunicativo dentro de un texto más extenso, habitualmente dialogado.

Según el Diccionario de la Real Academia (DRAE) es una interjección de etimología imprecisa ("Voz expresiva" equiparable al inglés hello y alemán hallo ${ }^{4}$ ) con los siguientes significados:

1. interj. U. como salutación familiar.

2. interj. p. us. U. para denotar extrañeza, placentera o desagradable. U. t. repetida.

3. interj. desus. Era u. para llamar a los inferiores. (s. v. hola, R.A.E, 2014)

En la acepción principal se califica hola como saludo "familiar" o, lo que es lo mismo, como perteneciente al registro coloquial o informal. En la segunda acepción, con la característica de "poco usada" se indica que denota extrañeza utilizándose repetida, valor que no hemos encontrado en ejemplos del siglo XXI, puesto que el nuevo sentido de sorpresa que analizaremos tiene entonación interrogativa, no aparece repetido y parte de un registro

3 Entre paréntesis recogemos la notación de las respectivas redes sociales en nuestros ejemplos del corpus.

4 En anteriores ediciones del DRAE se proponía la etimología árabe wa-llãh, 'Oh a ti', 'Por Dios', de la que Corominas y Pascual (1991-1997) discrepan y proponen, como recoge la actual edición del DRAE, la relación con las otras lenguas europeas. Covarrubias (2006) sugiere, en cambio, que procede la interjección latina heus (s. v. hola). 
coloquial. Mientras que el tercer supuesto ya añade el valor de "desusado" y que se utilizaba para llamar a los inferiores, siendo, en efecto, una de las funciones de la interjección en sus orígenes, en el siglo XVII (Faya y Vila 2013).

En el Diccionario del español actual (DEA) de Seco et alii (1999) se especifican y ejemplifican las dos principales acepciones citadas en el DRAE:

hola interj 1 (col) Se emplea como saludo al encontrar a una pers, esp si esta es conocida. |[...] 2 (lit) Expresa extrañeza. | RIriarte Carrusel 289: —iSeñor comisario Tengo que hacer una declaración... — ¡Hola! ¿Una declaración? (s.v., Seco et alii 1999)

En efecto, se caracteriza la acepción principal como "coloquial" y la segunda acepción como "literaria", lo que explicaría que en nuestro corpus no encontremos ningún caso de este valor. En la función de saludo se concreta que se emplea "al encontrar a una persona, especialmente si esta es conocida".

El registro coloquial del saludo durante el siglo XX se confirma en estudios sobre el lenguaje juvenil como el de Alba y Sánchez (1980), aunque deberíamos precisar que más que a personas conocidas, como indica el DEA, se trataría de un saludo dirigido a personas que ostentan el mismo rango social, es decir, es un saludo de igual a igual, frente a otros saludos como Buenos días, Buenas, etc. Ahora bien, cabría preguntarse si actualmente, en el siglo XXI, hola ha extendido su uso a situaciones no exclusivamente coloquiales, sino también formales, convirtiéndose en un saludo universal. De hecho, es frecuente encontrarlo en casos en que no hay un conocimiento mutuo: en numerosas páginas webs se recibe al nuevo usuario con un hola; las compañías telefónicas nos envían mensajes que comienzan con un hola; las entidades bancarias, las compañías eléctricas, etc. nos pueden saludar igualmente con un hola en sus páginas corporativas o en las facturas que nos envían; en algunos centros comerciales nos reciben con un hola gigante antes del aparcar... Ello puede deberse tal vez a la progresiva coloquialización del lenguaje a la que asistimos, precisamente incrementada por el uso de los medios digitales (Mancera 2014; López Serena 2014), pero, en todo caso, es un hecho que hoy día hola es un saludo muy frecuente en cualquier contexto.

La Nueva Gramática (NGRAE, 2009) sitúa ;Hola! entre las "interjecciones apelativas" $(\$ 32.1 \mathrm{~h})$ también llamadas directivas u orientadas hacia el oyente (frente a las interjecciones expresivas) y añade:

Muchas interjecciones y locuciones interjectivas, llamadas a veces 'formularias', caracterizan los comportamientos sociales o rituales reglados verbalmente. Entre ellas están las que se usan en los saludos y en las despedidas: hola, adiós, salud, abur o agur, epa [...] $(\S 32.6 \mathrm{a})$

En este caso se da una pincelada pragmática, tanto al hablar del carácter apelativo, orientado al oyente, como al referirse al valor formulario y, por tanto, cortés, pero realmente en ningún momento se menciona el valor pragmático fundamental de apertura del discurso. En efecto, desde el punto de vista pragmático, hola es un marcador conversacional que tiene una función fática de apertura del canal, es decir, en cuanto saludo, su finalidad primordial, además del propio saludo, es la de iniciar el intercambio comunicativo. Esta es la función más habitual que encontramos en nuestro corpus: 
(1) 2015/07/16, 14:33 - H1: Hola

2015/07/16, 14:36 - M1: Hola caracola

2015/07/16, 14:36 - M1: Mañana H3 y yo hemos hablado de quedar

2015/07/16, 14:36 - M1: Quien se apunta?? (WA, 2015/16 ago-mar)

Puede aparecer autónomo constituyendo un enunciado o una intervención, como vemos en el primer informante (H1), o iniciando un enunciado mayor, como se comprueba a partir de la segunda intervención de (1), la del informante M1. También puede aparecer tanto en una intervención iniciativa (H1) como reactiva (caso de M1).

Como apunta la Real Academia (NGRAE, 2009), tiene un marcado carácter apelativo y, por ello, podríamos incluirlo entre los "enfocadores de la alteridad" dentro de la clasificación de los marcadores conversacionales que realizan Martín y Portolés (1999), pues desempeñan una función interaccional, orientada hacia el enunciatario: aparecen frecuentemente con modulación exclamativa; pueden constituir un enunciado autónomo en el caso de que precedan al enunciado (que en nuestro caso es lo habitual); comparten propiedades pragmáticas con los 'marcadores de modalidad' (Ídem); expresan estrategias de cooperación entre los participantes en la conversación; con frecuencia son indicadores de la cortesía verbal; son operadores; se duplican con frecuencia, especialmente en las intervenciones reactivas (Martín y Portolés, 1999: 4171-4172).

Ahora bien, además de esta función prototípica de operador fático y cortés, hola tiene otro valor que no viene recogido en los diccionarios, a pesar de existir prácticamente desde su origen, como nos indican Faya y Vila (2013). Nos referimos al uso exclusivamente apelativo para comprobar la presencia del interlocutor. En estos casos suele conllevar una entonación interrogativa:

(2) 20/08/2016 13:03:38: H1: ya estoy

20/08/2016 13:09:49: H1: ireeeeeeene

20/08/2016 13:18:05: H1: hola?

20/08/2016 13:19:56: M1: Ya voy Antonio

20/08/2016 13:20:07: M1: No voy a estar ahí pegada a la pantalla esperando

20/08/2016 13:20:19: H1: no es eso

20/08/2016 13:20:20: H1: xD

20/08/2016 13:20:31: H1: simplemente a ver si estabas

20/08/2016 13:20:34: H1: a lo mejor ya no podias

20/08/2016 13:34:26: M1: Ya estoy (WA 2015/16 ago-mar)

En el informante H1 de (2) pretende comunicarse con la informante M1 y profiere los tres mensajes de chat iniciales: un enunciado afirmativo que abre su discurso indicando que ya está en línea, seguido de un vocativo seis minutos después. Al no recibir respuesta, casi nueve minutos más tarde dice hola?, con un valor claramente apelativo de comprobación de la copresencia del interlocutor. El propio hablante explica más adelante el sentido de dicho enunciado: "simplemente a ver si estabas", ya que debe justificarse ante la incomodidad de su interlocutora, que había interpretado como descortés su insistencia, la de H1. Es un uso

5 Seguimos la notación del corpus MESa: para los ejemplos de Whatsapp aparece en primer lugar la fecha, seguida de la hora y el informante numerado junto a la letra que indica el sexo (H, hombre; $\mathrm{M}$, mujer). El subrayado de la forma hola es nuestro. 
similar al que se da en situaciones cotidianas cuando entramos en una casa o en una estancia donde no sabemos si hay alguien o esperamos que alguien nos reciba. Vila y Falla (2013: 890) observan este valor en el teatro de Calderón de la Barca en un 20\% de los casos analizados.

Precisamente el estudio pragmático de hola en el teatro de Calderón de Vila y Falla (2013) nos aclara las acepciones recogidas en el DRAE ya comentadas: la función más habitual del siglo XVII era la de llamar un superior en la jerarquía social a un inferior (los nobles a los criados, habitualmente), en un $64 \%$ de los casos analizados en el teatro de Calderón (Vila y Falla 2013: 888), lo que se corresponde con la tercera acepción del DRAE. Vila y Falla (2013: 890) concretan que en estos casos hola es un marcador que sirve para llamar la atención sobre el acto de habla que sigue, que es de tipo directivo (órdenes o mandatos, en el $62 \%$ de los casos). Este uso va a ir disminuyendo durante el siglo XVIII hasta desaparecer a mediados del XIX, ya que va a ser sustituido, como se deduce del estudio citado, por la función de saludo. De hecho, Vila y Falla (2013: 892) documentan en el CORDE el primer ejemplo de hola como saludo en 1842, aunque no se registra en el Diccionario de Autoridades hasta finales del XIX. La evolución coincide significativamente con los cambios sociales del siglo XIX.

Pero, junto a estos dos valores, a partir de la segunda mitad del XVIII y durante todo el siglo XIX se documenta en el CORDE otra función, la de denotar extrañeza (segunda acepción del DRAE), convirtiéndose en la más frecuente (un 72\% de los casos). Ahora bien, hay que tener en cuenta que en todos estos casos se trata de textos literarios, con lo cual no sabemos el alcance que pudo tener en la lengua oral de la época. Esto explica por qué el DEA, teniendo en cuenta además que su uso es mucho más reducido, lo califica como "literario".

Podríamos resumir la evolución diacrónica de las funciones pragmáticas del marcador hola en el siguiente cuadro:

\begin{tabular}{|c|c|c|c|c|c|}
\hline Funciones & Siglo XVII & Siglo XVIII & Siglo XIX & Siglo XX & Siglo XXI \\
\hline Apelativa & $\begin{array}{c}\text { Llamar un } \\
\text { superior a } \\
\text { un inferior }\end{array}$ & $\begin{array}{c}\text { Llamar un } \\
\text { superior a } \\
\text { un inferior }\end{array}$ & $\begin{array}{c}\text { Desaparece } \\
\text { hacia } 1850\end{array}$ & & \\
\cline { 2 - 7 } & $\begin{array}{c}\text { Comprobar } \\
\text { la presencia } \\
\text { del otro }\end{array}$ & $\begin{array}{c}\text { Comprobar } \\
\text { la presencia } \\
\text { del otro }\end{array}$ & $\begin{array}{c}\text { Comprobar } \\
\text { la presencia } \\
\text { del otro }\end{array}$ & $\begin{array}{c}\text { Comprobar } \\
\text { la presencia } \\
\text { del otro }\end{array}$ & $\begin{array}{c}\text { Comprobar la } \\
\text { presencia del otro }\end{array}$ \\
\hline Saludo & Aparece & $\begin{array}{c}\text { Saludo } \\
\text { coloquial } \\
\text { entre iguales }\end{array}$ & Saludo \\
\hline $\begin{array}{c}\text { Denotar } \\
\text { extrañeza }\end{array}$ & Apacia 17540 & $\begin{array}{c}\text { Muy } \\
\text { frecuente } \\
\text { en textos } \\
\text { literarios }\end{array}$ & $\begin{array}{c}\text { Solo en } \\
\text { el ámbito } \\
\text { literario }\end{array}$ & \\
\hline $\begin{array}{c}\text { Sorpresa y } \\
\text { desacuerdo }\end{array}$ & & & & & \\
\hline
\end{tabular}


Se constata que la función apelativa de "comprobar la presencia del otro", a pesar de no ser la más frecuente, ha existido en todas las épocas y, no obstante, no suele aparecer recogida en los diccionarios. Por otra parte, la función apelativa de llamada e inicio de discurso tiene una continuidad histórica entre el marcador original de interpelar a un inferior de los siglos XVII y XVIII y el posterior saludo coloquial de la segunda mitad del XIX, que continúa en el XX y el XXI.

Ahora bien, el valor de "denotar extrañeza" del siglo XIX nos permite observar que el operador apelativo y fático, que apunta inicialmente al receptor, también tiene una potencialidad modal, que, en dirección opuesta, refleja la subjetividad del hablante, algo que no es extraño en otras interjecciones y tampoco en otros marcadores. Y esto mismo es lo que vamos a observar en el nuevo uso de ¿hola? como operador de sorpresa y desacuerdo en textos conversacionales del siglo XXI.

\section{EL NUEVO OPERADOR DEL DESACUERDO}

Si hola con la función de saludo puede aparecer en intervención iniciativa o reactiva, en el caso de la nueva función modal de ¿hola?, solo aparece en intervención reactiva:

(3) Usuario $1(\mathrm{H})$ : @perezreverte a los que pagan impuestos les controlan, y a los negros que venden ilegal en la playa etc ni les dicen nada... en fin Usuario 2 (H): @usuario1@perezreverte ahora la culpa la van a tener los negros de la playa, no te jode

Usuario $1(\mathrm{H})$ : @usuario2@perezreverte hola? Aprende leer luego a escribir Usuario $2(\mathrm{H})$ : @usuario1@perezreverte que vas, de académico

Usuario $1(\mathrm{H})$ : @usuario2@perezreverte no dije que la culpa es de los negros pero allá tu! Dije que vayan a ellos a marear. Fin (TW 2016 may ART 20)

En esta conversación de Twitter observamos que el usuario 1 se sorprende ante la interpretación que realiza el usuario 2 de su intervención inicial y contesta hola? Aprende leer [sic] luego a escribir, es decir, con este operador modal y argumentativo muestra sorpresa y desacuerdo (no está de acuerdo con la afirmación del usuario 2) y sitúa seguidamente un reproche en forma imperativa (Aprende...). En la siguiente intervención, el usuario 1 justifica esta reacción descortés diciendo el motivo de su desacuerdo.

Cuando aparece en intervención iniciativa se trata siempre de una reacción a un discurso o un hecho anterior:

(4) 2018/04/13, 19:01, M1: Mm hola?

2018/04/13, 19:01, M1: [2018/04/13, 17:36, M2: Mariiia

2018/04/13, 17:36, M2: 8:45

2018/04/13, 17:36, M2: En mi casa o en la vacaa]

2018/04/13, 19:01, M1: Q flipada JAJAJ

2018/04/13, 19:07, M3: Ya ves, quilla, a mi me ha dicho lo mismo, pero bueno, en verdad lo prefiero porque así antes de comer estamos aquí.

2018/04/13, 19:08, M1: Po na a levantarse temprano :- :-2018/abril)

En este caso la chica M1 expresa un hola? precedido de una interjección a raíz de una conversación previa que ha mantenido antes (a las 17:36) con M2, la cual aquí reproduce 
para comentarla con M3. El enunciado de hola? va seguido de $Q$ flipada JAJAJ, es decir, exclamaciones enfáticas que refuerzan la sorpresa y el desacuerdo apuntado por hola? a partir de la hora propuesta para la cita por M2, que M1 considera demasiado temprana. La interjección inicial $(\mathrm{Mm})$ al mismo tiempo que enfatiza el valor del hola? funciona como índice de que se trata de una reflexión sobre algo dicho u ocurrido y así se evita la posible confusión con el ¿hola? apelativo.

Así pues, ¿hola? puede aparecer en el inicio de una intervención reactiva de desacuerdo, precediendo a un enunciado que puede ser un ataque, como hemos observado en (3) y también en (5):

(5) 2/2/17, 9:17 - M1: M4, mira a ver si puedes pillar cosillas güenas como la de la herradura para cuando vayamos jujuju

2/2/17, 9:28 - M4: Como?

2/2/17, 9:28 - M4: Jajaj

2/2/17, 9:58 - M3: Hola?

2/2/17, 9:59 - M3: A M1 se le ha ido la pinza?

2/2/17, 9:59 - M3: Espera espera...

2/2/17, 9:59 - M3: Quieres fumar porros???

2/2/17, 9:59 - M3: Flipo

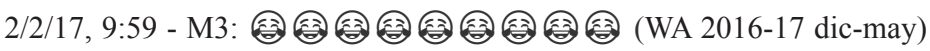

Aquí, Hola? introduce el enunciado A M1 se le ha ido la pinza? que, aunque es atenuado por la interrogación, es un ataque descortés hacia M1. Al final también se atenúan estos ataques mediante los emoticonos de las caritas sonrientes. El hecho de que el Hola? y el resto del enunciado vayan en intervenciones diferentes aquí no es significativo, ya que en Whatsapp es habitual la escritura de enunciados segmentados en varias intervenciones. Otras veces el ataque directo viene suavizado en forma de deseo y de reflexión como en (6):

(6) Usuario $3(\mathrm{M})$ : Genevieve, a mi me dan igual las Navidades pero pienso en el prójimo, no en mi propio ombligo. De lo q roba el gobierno ya me quejo y créeme q no he votado al PP, pero creo q hay q ser críticos incluso con aquellos con los q normalmente estamos de acuerdo. La auto-crítica y la humildad a veces ayuda a mejorar y a avanzar.. La base de la democracia es aceptar q otro pueda pensar diferente a ti, la base es el diálogo y la tolerancia. Es curioso q los q más se quejan de q otros son fascistas son los q más se comportan como tal. Q tengas buen día.

Usuario 13 (M): [Mención al usuario 3] mira payasa, el día que a ti por cristiana te persigan en la calle y te den una paliza que casi te mate como me pasó a mí por ser gay me sueltas otra vez está gilipollez. Mientras tanto lee un poco más, abre un poco más los ojos y aprende lo que son los derechos fundamentales de todo ser humano. Y otra cosa que debes aprender a diferencia, lo que es una elección personal, tu religión, a lo que es tu sexualidad, ser homosexual, eso no se elige.

Usuario $3(\mathrm{M})$ : [Mención al usuario 13] a los cristianos ya les persiguieron por ello, estudia un poquito que seguro q no te vendrá mal. Yo no estoy en contra del orgullo gay, es más, estoy a favor y creo q los prejuicios de los humanos (como tu prejuicio y falta de respeto al llamarme a mi payasa) es lo q enferma a la sociedad y la destruye a la humanidad, porque ante todo debajo de la piel hay sentimientos y da igual del sexo q seas y por ello, se debe luchar. Lo único q he dicho q hay q gobernar para TODOS, si a ti q yo diga q hay q gobernar para todos es una ofensa tan grave y por eso decides 
llamarme payasa, pues allá tú, el q lleva la rabia y la ira dentro eres tú, no yo. Usuario 14 (H): Hola? Espero que nunca te maltraten, ni te juzguen como lo han hecho con nosotros. Por que qu tiene que ver la Navidad con esto.???!!! Madre mía (FB 2016 jun CAR 05)

El usuario 14, que se identifica dentro del colectivo gay, expresa su desacuerdo con el argumentario del usuario 13 y emite un enunciado desiderativo no exento de ironía: Espero que nunca te maltraten, ni te juzguen como lo han hecho con nosotros y, por tanto, descortés hacia la imagen del usuario 13 (sobre la descortesía y los elementos descorteses, cf. Fuentes y Alcaide, 2009; Fuentes et alii, 2011).

Ahora bien, este operador también puede aparecer dentro de una misma intervención. Entonces establece una relación pragmática de sorpresa con respecto al enunciado anterior $\mathrm{y}$, al mismo tiempo, opera sobre el enunciado subsiguiente, que puede expresar:

a) Énfasis de la sorpresa:

(7) 2015/11/17, 09:45, H3: q coño pasa? enserio van a meter bomba en españa? francia en guerra? exigen militares de europa? hola? petroleo? (WA 2015/16 ago-mar)

Aquí el hablante expresa su estupefacción por las últimas noticias de ese día que el propio informante ha compartido en un enlace en la intervención anterior. El hola? no hace más que intensificar la sorpresa de los enunciados precedentes y del siguiente.

b) Justificación o petición de explicación:

(8) 2016/01/25, 07:17 - H5: H1! Felices 27!!! Ya nos vamos haciendo mayores!!

2016/01/25, 07:17 - H5: [emoticonos de 27 tartas]?

2016/01/25, 07:48 - H3: Felicidades!!

2016/01/25, 07:48 - H3: Dios mio, siempre cumplis un año mas

2016/01/25, 07:48 - H3: 26 ok, 27???? Hola?? Y la boda? y los niños?

2016/01/25, 07:51 - H5: Yo me caso ya mañana

2016/01/25, 07:52 - H3: ?

2016/01/25, 08:23 - H1: te agradezco el detalle H5, pero seria incapaz de comerme 27 tartas ! (WA 2015/16 ago-mar)

El informante H3 de (8) se sorprende de que H1 cumpla 27 años, expresándolo con el hola? seguido de la justificación: "Y la boda? y los niños?", es decir, considera que con esa edad debería haberse casado o tener hijos.

c) Desacuerdo o contraargumento:

(9) Usuario 15 (M): @policia promoviendo estereotipos machistas... lo que hay que aguantar Usuario 11 (no identificado): @usuario15@policia ¿Es machista que una mujer le mire el móvil a su novio y la policía critique eso? ¿Hola? Es hembrista que ella haga eso. Usuario15 (M): @usuario11@policia es machista pensar que todas las mujeres hacen eso y ejemplificar así nos hace quedar como celosas controladoras (TW 2016 oct PON 01)

El Usuario 11 no está de acuerdo con el Usuario 15 y lo recogen en la entonación interrogativa de su primer enunciado, seguido del ¿Hola?. A continuación propone en el siguiente enunciado su postura contraria. 
Se comprueba que en estos casos en que aparecen en la misma intervención hay bastantes ecos polifónicos. El enunciador menciona a menudo palabras de otros locutores, frecuentemente mediante enunciados interrogativos, como vemos en estos tres ejemplos (7, 8 y 9). A veces se puede interpretar como una especie de diálogo del locutor consigo mismo. En algunos casos, se comprueba fehacientemente que se trata de una reproducción de un diálogo:

(10) 2015/06/25, 00:28, H3: osea que se me cae la cerveza porque voy borracho. Me quedo SIN cerveza. Y me llega el gorilla, agarrandome fuerte por el brazo(me ha hecho daño) y me dice en PUTO RUMANO, que qué coño hago? hola? me he quedao sin cerveza, ahora me tengo que conprar otra porque la hora se ha acabado. Me vienes a dar por culo? Y hacerme daño? IMBEZIL? te mato idiota... me ha jodido toda la puta noche (WA 2015/16 ago-mar)

En este caso, H3 está narrando la situación de la noche anterior y reproduce en una mezcla de estilo indirecto (me dice...que qué coño hago) y directo (hola? me he quedao sin cerveza...), por lo que habría que clasificarlo directamente entre los ejemplos de intervención reactiva que inicia, en esta ocasión, una justificación.

Se ha podido comprobar que en todos los supuestos analizados ¿Hola? va acompañado por uno o ambos signos de interrogación, e incluso a veces por una interjección, como en (4), lo cual subraya la característica entonación ascendente similar a la del ¿hola? apelativo para la comprobación de la presencia del interlocutor.

Por otra parte, nos confirma que estamos ante un operador argumentativo el hecho de que junto al ¿hola? aparecen elementos tanto atenuadores como reforzadores del desacuerdo:

a) Elementos atenuadores:

La modalidad interrogativa puede funcionar como elemento atenuador, como hemos visto en (5): A M1 se le ha ido la pinza?; en (7): exigen militares de europa? hola? Petroleo?; y en (8): 27???? Hola?? Y la boda? y los niños?.

También atenúa la justificación de la sorpresa: hola? me he quedao sin cerveza, ahora me tengo que conprar otra porque la hora se ha acabado (10).

Otros atenuadores son las expresiones fáticas, como espera, espera (5), o modales, como Flipo (5). Igualmente contribuyen a la atenuación las risas $J A J A J$ (4 y 5) y los emoticonos de caras sonrientes (4 y 5), que restan dramatismo y descortesía al texto escrito precedente.

b) Elementos reforzadores:

A veces la entonación interrogativa forma parte de una estrategia reforzadora, puesto que no pretende quitar fuerza a un enunciado descortés, sino, al contrario, se trata de una pregunta retórica que conlleva una descalificación del interlocutor:

(11) Usuario 3 (M): @sanchezcastejon @PSOE \#GrabacionesInteriorM4 Pedro es es la democracia, juego limpio como el q tú practicas. Lamentable Ppodemos Usuario 4 (no identificado): @Guinzomanuela@sanchezcastejon@PSOE PPodemos 


\begin{abstract}
XDDDDDDDDDDDDDD El PSOE no ha gobernado durante 30 años a turnos con el PP no... qué torpe

Usuario 5 (H): @sanchezcastejon@PSOE Les falta mucho respeto a PP y Podemos, por eso son amiguitos en las investiduras contra el PSOE

Usuario6 (mujer): @usuario5@sanchezcastejon@PSOE hola? Pero tú estás al tanto de la actualidad política de tu país? (TW 2016 jun 22 SAN 02)
\end{abstract}

En este sentido, podemos encontrar también el uso de imperativos, como en Aprende leer [sic] luego a escribir (3), con su habitual carga descortés, de insultos, como imbécil, idiota (10), de interjecciones, exclamaciones y valoraciones; Madre mía (6), Q flipada (4).

También son reforzadores del desacuerdo los conectores argumentativos Pero (11) y Porque (6). Es significativo el caso de Pero en (11); se puede comprobar que no conecta realmente el enunciado que encabeza ni con el de hola? ni mucho menos con la intervención previa, sino que se trata de un reforzador de la fuerza argumentativa del desacuerdo propiciado ya desde el hola? Inicial.

El operador ¿hola? actúa, por tanto, en una doble dimensión pragmática: en el plano modal indica sorpresa, extrañeza del hablante ante lo que oye o sucede, mientras que en el plano argumentativo expresa desacuerdo y contraargumentación, a menudo acompañada de descortesía verbal, y ello tanto en intervenciones reactivas dentro del discurso dialógico, como en una misma intervención de carácter monológico.

Esta multidimensionalidad no es extraña, pues ya se observa en otros enfocadores de la alteridad (hombre, vamos, mira, oyes, ¿sabes?). Un caso muy similar es el de venga, estudiado en Twitter por López Quero (2018), que presenta valores modales y argumentativos $\mathrm{y}$, entre estos, también el de desacuerdo.

\title{
6. ORIGEN DEL NUEVO OPERADOR DEL DESACUERDO
}

Consideramos que el nuevo valor de ¿hola? procede del marcador fático hola que hemos comentado en el apartado 4. De hecho, hemos comprobado que históricamente ya había tenido un uso modal, al denotar extrañeza fundamentalmente durante el siglo XIX:

(12) Hola, hola ¿también soy usía? Pues esto sí que me llena de asombro. (CORDE, 1874, Benito Pérez Galdós, Napoleón en Chamartín, p. 95)

No obstante, pensamos que el uso actual que comentamos no tiene relación directa con el señalado por sus diferentes condicionantes socio-pragmáticos: mientras aquel fue un uso circunscrito desde finales del siglo XIX y durante el XX a los textos literarios escritos, en nuestro caso se trata, por el contrario, de un discurso con características orales y coloquiales, además de otros aspectos como el prosódico (no hay constancia de la entonación interrogativa en el uso característico del XIX).

Hemos comprobado, en efecto, que el operador ¿hola? del siglo XXI tiene un uso predominantemente coloquial ${ }^{6}$, puesto que las redes sociales se caracterizan, como dijimos al principio, por un predominio del registro coloquial y ciertamente la mayoría de los ejemplos

6 En cuanto a la variable de sexo, aparece de manera indistinta tanto en hombres como en mujeres en los casos de nuestro corpus $(50 \%)$. 
pertenecen a esa variable. Ahora bien, podemos observar algún ejemplo de cierto grado de formalidad:

(13) Usuario $1(\mathrm{H})$ : Buenos días Vueling y a quien lo lea... llevo una semana en Londres por trabajo y he querido traerme este finde a mi hija, 11 años. Cuando contraté el servicio de acompañamiento de menores, 4 veces más caro que el vuelo en sí, el operador me dijo que DNI. Y no... hoy se ha quedado en tierra, sin viaje y llorando. Hola??? Qué tipo de formación dan Uds a sus empleados??? (IG 2016 nov-dic VUE 10)

En este ejemplo vemos que un usuario de Instagram hace este comentario en la página oficial de una compañía aérea. La intervención comienza en un tono formal; el saludo inicial es "Buenos días" y se dirige a la compañía con el apelativo de cortesía "Uds". Esto puede ser una muestra del proceso de gramaticalización de este operador. No obstante, es un proceso en curso, como se comprueba aún en la dependencia de la curva entonativa (Traugott y Trousdale 2010, Fuentes 2012), un rasgo que aún es necesario para identificar al operador y, por tanto, no lo convierte en totalmente autónomo y gramaticalizado.

Así pues, este nuevo valor de desacuerdo parte de las potencialidades pragmáticas y semánticas del marcador original, pero es de nueva generación en el registro coloquial del siglo XXI en España. Ciertamente, parte de los significados prototípicos del operador fático hola, esto es, el aspecto interactivo de apelación al receptor, que tiene valor prospectivo, y el saludo, que suele servir como apertura del discurso, conllevando según el contexto cierto grado de cortesía. Partiendo de estas funciones pragmáticas, para que se dé la interpretación del nuevo valor de desacuerdo, deben darse ciertas condiciones de descontextualización: a) el discurso ya está iniciado (no se puede interpretar la apertura del discurso); b) los interlocutores están conectados y activos o no hay interlocución pues se trata de un discurso monológico (se anula el carácter apelativo de llamada o de comprobación de la presencia del interlocutor).

Esto lleva a la inferencia inicial de que se ha roto el contacto o no hay interlocutor. El carácter apelativo se transmuta en un valor argumentativo ya que convierte el enunciado en un enunciado reactivo. El hecho de que el oyente compruebe que el contexto sigue intacto, es decir, hay copresencia de los interlocutores, el canal está abierto o se trata de un discurso monológico, lleva a la interpretación reactiva y descortés. A su vez el hablante aprovecha esa potencialidad de aparente reinicio de la interlocución para expresar su sorpresa y desacuerdo de manera enfática y contundente, haciendo uso de una gran economía lingüística, ya que con una sola lexía, como es ¿hola?, expresa todas estas inferencias.

Se observa, por tanto, que se ha seguido el camino inverso de muchos marcadores que a menudo evolucionan de operadores modales y argumentativos a meros marcadores fáticos (¿sabes?, tío, macho,...), como señalamos al principio. Ahora bien, es cierto que interviene, como en la mayoría de los operadores, el proceso de subjetivización, a través del cual el hablante hace explícitas sus perspectivas y actitudes (Martí 2008: 85):

Por el proceso de subjetivización, el hablante se hace presente para mostrar su relación con el interlocutor (intersubjetividad) o/y lo enunciado, estableciendo diversas relaciones dentro del acto comunicativo de acuerdo con diversos fines. Por otro lado, la subjetivización tiene que ver con el contenido sobreentendido, con las implicaciones de que habla la pragmática, implicaciones que empiezan siendo ocasionales, pero que progresivamente van generalizándose hasta convencionalizarse en algún caso. 
Es algo que resulta totalmente aplicable al caso que estamos comentado: el hablante con ese aparente reinicio de la interlocución muestra los valores modales de la sorpresa y el desacuerdo. A partir de aquí, según el contexto, el operador puede adquirir también una función pragmática en el plano argumentativo iniciando un argumento reactivo que puede conllevar según los casos diferentes grados de descortesía:

(14) ZineMÁS: Pues mi recomendación es que veas "InsideOut". Te va a encantar. A mí "El Señor de los Anillos" me apasiona pero tampoco me gustó la trilogía del Hobbit. Eso sí: De "StarWars" me gusta todo, absolutamente todo. Un saludo y gracias por comentar ZineMÁS.

Usuario 50 (M): Hola? Dijiste Valdemort en vez de voldemort : : : :

ZineMÁS: Bueno, no es para tanto. (YT 2016-17 oct-sep ZIN 1)

En este ejemplo el Usuario 50 muestra su sorpresa porque en el canal ZineMás de Youtube se ha puesto un vídeo hablando de, entre otras películas, de Harry Potter donde se ha pronunciado mal el nombre de uno de los personajes, como explica en el enunciado que inicia el ¿hola? El posible carácter descortés de este enunciado viene atenuado por las subsiguientes caritas sonrientes, pero aún así el interlocutor, ZineMás, contesta Bueno, no es para tanto, por lo que se puede apreciar que ha entendido el enunciado del Usuario 50 con fuerza argumentativa excesiva y ciertamente descortés.

\section{CONCLUSIONES}

Hemos comprobado, por tanto, que la evolución de un marcador fático como hola hacia un operador modal y argumentativo demuestra la polifuncionalidad y versatilidad de los marcadores conversacionales.

En este caso se da una evolución inversa a la habitual, que suele ir de lo modal a lo meramente enfático o fático. Aquí se aprovecha la potencialidad inherente de la interjección hola, que tiene un valor apelativo e interactivo, para expresar valores modales de sorpresa y desacuerdo, tanto en el discurso dialogado como en el monológico.

Es un valor que nace del marcador actual generalizado del saludo (hola), aunque históricamente hay concomitancias con otros valores similares. La descontextualización del saludo (el discurso está iniciado y los interlocutores activos) provoca la interpretación de sorpresa y/o desacuerdo y convierte lo que era cortés en descortés, siguiendo un proceso de subjetivización del discurso. Puede tener una función modal, argumentativa o ambas a la vez.

Aparece tanto en hombres como en mujeres, fundamentalmente dentro del registro coloquial y conversacional, aunque hay algunos ejemplos de cierto grado de formalidad.

\section{REFERENCIAS BIBLIOGRÁFICAS}

Alba de Diego, V. y J. Sánchez Lobato (1980). "Tratamiento y juventud de la lengua hablada. aspectos sociolingüísticos", Boletín de la Real Academia Española, 60, 219, pp. 95-130.

Álvarez-Ejzenberg, F. (2015). "El marcador discursivo 'dale' desde la perspectiva de la unicidad del signo", CLAC, 62, pp. 54-75.

Briz Gómez, A. (1998). El español coloquial en la conversación: esbozo de pragmagramática. Barcelona: Ariel. 
Bosque, I. y V. Demonte (eds.) (1999). Gramática descriptiva de la lengua española. Madrid: Espasa. Corominas, J. y J. A. Pascual (1991-1997). Diccionario crítico etimológico castellano e hispánico. Madrid: Gredos.

Covarrubias, S. (2006). Tesoro de la lengua castellana o española (Arellano y Zafra, eds.). Madrid: Biblioteca Áurea Hipánica.

Crystal, D. (2001). Language and Internet. Cambridge: Cambridge University Press.

Faya Cerqueiro, F. y Z. Vila Carneiro (2013). "Análisis pragmático del marcador 'hola' en el teatro de Calderón de la Barca", Bulletin of Hispanic studies, 90, 8, pp. 883-896.

Fuentes Rodríguez, C. (2001). "Los marcadores del discurso, ¿una categoría gramatical?", en E. Méndez et alii (eds.). Indagaciones sobre la lengua. Estudios de filología y lingüistica españolas en memoria de Emilio Alarcos. Sevilla: Universidad de Sevilla, pp. 323-348.

Fuentes Rodríguez, C. (2012). "Sobre la gramaticalización de los operadores discursivos, como no podía ser de otra manera", $L E A, 34,1$, pp. 27-58.

Fuentes Rodríguez, C. (2013). "La gramática discursiva: niveles, unidades y planos de análisis", Cuadernos de AISPI, 2, pp. 9-30.

Fuentes Rodríguez, C. (2014). "Los límites del enunciado”, Estudios de Lingüistica del Español, 35, pp. 137-160.

Fuentes Rodríguez, C. (2017). "Macrosintaxis y lingüística pragmática”, CLAC, 71, pp. 5-34.

Fuentes Rodríguez, C. (2017[2000]). Lingüística pragmática y análisis del discurso. Madrid: Arco Libros.

Fuentes Rodríguez C. y E. Alcaide (2002). Mecanismos lingüisticos de la persuasión. Madrid: Arco Libros.

Fuentes, C. y Alcaide, E. (eds.) (2009). Manifestaciones textuales de la descortesía y agresividad verbal en diversos ámbitos comunicativos. Sevilla: UNIA.

Fuentes, C., E. Alcaide y E. Brenes (eds.) (2011). Aproximaciones a la (des)cortesía verbal en español. Berna: Peter Lang.

Koch, P. y W. Oesterreicher (1990 [2007]). Lengua hablada en la Romania: español, francés, italiano. Madrid: Gredos.

López Quero, S. (2018). “La función apelativa del marcador discursivo venga en Twitter”, Onomázein, Revista de lingüistica, filología y traducción, 39, pp. 48-65.

López Serena, A. (2014). "De la oralidad fingida a la oralidad simuladora de la realidad: reflexiones en torno a la coloquialización del discurso como estrategia mediática", Española Actual, Revista del español vivo, 102, pp. 37-75.

Martí Sánchez, M. (2008). "La hipótesis de la subjetivización en la pragmaticalización / gramaticalización de los operadores pragmáticos", Paremia, 17, pp. 79-90.

Mancera Rueda, A. (2014). "Cortesía en 140 caracteres: interacciones en Twitter entre periodistas y prosumidores", Revista de filología de la Universidad de La Laguna, 32, pp. 163-180.

Mancera, A. y A. Pano (2013). El discurso politico en Twitter. Análisis de mensajes que "trinan". Barcelona: Anthropos.

Martín Zorraquino, M. A. y J. Portolés, (1999). "Los marcadores del discurso". En Bosque, I. y V. Demonte (eds.). Gramática descriptiva de la lengua española. Madrid: Espasa, pp. 4051-4213.

Moreno Benítez, D. (2019). "El vocativo en la estructura del enunciado". En Fuentes, C. y S. Gutiérrez (eds.). Avances en macrosintaxis. Madrid: Arco Libros, pp. 89-128.

Narbona, A. (2000). "Sintaxis Coloquial”. En Alvar, M. (dir.). Introducción a la Lingüística Española. Barcelona: Ariel, pp. 463-478.

Padilla, M. S. (2016). "Marcadores y partículas discursivas interactivas en el entorno político/periodístico de Twitter", Philologia Hispalensis, 30, 1, pp. 193-212.

Pano, A. y A. Mancera (2014). "La 'conversación' en Twitter: las unidades discursivas y el uso de marcadores interactivos en los intercambios con parlamentarios españoles en esta red social”, Estudios de Lingüistica del Español, 35, 1, pp. 234-268. 
RAE (2009). Nueva gramática de la lengua española. Madrid: Espasa Libros.

RAE (2014). Diccionario de la lengua española. Madrid: Espasa-Calpe.

Seco, M., O. Andrés, y G. Ramos (1999). Diccionario del español actual. Madrid: Aguilar.

Traugott, E. y G. Trousdale (eds.) (2010). Gradience, gradualness and gramaticalization. London: John Benjamins.

Van Dijk, T. A. (1983). La ciencia del texto. Barcelona: Paidós.

Yus Ramos, F. (2010). Ciberpragmática 2.0. El uso del lenguaje en Internet. Barcelona: Ariel. 